\title{
Rudolf Otto e Lutero: uma tentativa de compreender a sua relação, a partir de "O Sagrado", de Otto
}

\author{
Rudolf Otto and Luther: \\ an attempt to understand their relation based on "The Sacred" of Otto
}

Martin Timóteo Dietz*

\begin{abstract}
Resumo
O presente artigo procura auscultar mais de perto a relação do multifacetado teólogo da virada dos séculos XIX para XX com o ex-monge agostiniano de Wittenberg. Seria O Sagrado, no fundo, nada mais que uma atualização do pensamento de Lutero para os dias da Primeira Guerra Mundial, quando foi lançado? Que a ocupação com Lutero é, para Otto, bem mais que apenas episódio isolado, é fácil de imaginar quando se leva em consideração que já a tese doutoral, publicada em 1898, havia se ocupado com Lutero, especificamente com a pergunta pela compreensão do Espírito Santo, por aquilo que entrementes a teologia acadêmica se acostumou a denominar de Pneumatologia.
\end{abstract}

Palavras-chave

Rudolf Otto. Martim Lutero. O Sagrado.

\begin{abstract}
This article seeks to sound out more deeply the relation of the multifaceted theologian from the turn of the 19th to the 20th century with the Agostinian ex-monk of Wittenberg. Could The Sacred, down deep, be nothing more than an updating of Luther's thought for the days of the First World War, when it was released? That the occupation with Luther is, for Otto, much more than just an isolated episode, is easy to imagine when one takes into consideration that the doctoral thesis, published in 1898, had already occupied itself with Luther, specifically with the issue about the comprehension of the Holy Spirit, about that, which, in the mean time, academic theology has come to call Pneumatology.
\end{abstract}

Keywords

Rudolf Otto. Martin Luther. The Sacred.

[Texto recebido em junho de 2018 e aceito em junho de 2018, com base na avaliação cega por pares realizada por pareceristas ad hoc]

* Professor da Faculdades EST. Atua na Cátedra Contextual de Pesquisa em Lutero junto à Faculdades EST. E-mail: matrin.dietz@est.edu.br 


\section{Considerações iniciais}

Oneide Bobsin informa que intérpretes "de O Sagrado afirmam que foram leituras de Lutero e da Bíblia que levaram [Rudolf] Otto a compreender o numinoso" da forma como o expõe na mencionada obra. ${ }^{1}$ Hermann Brandt, por sua vez, constata: "Salta aos olhos a influência de Martim Lutero" sobre o famoso escrito de Otto. ${ }^{2}$ E, de fato, não apenas todo um capítulo de O Sagrado é dedicado ao "numinoso em Lutero",3 como o Reformador do séc. XVI é mencionado mais de dez vezes - fora do referido capítulo - ao longo da obra, quase sempre de forma positiva.

O presente artigo procura auscultar mais de perto a relação do multi-facetado ${ }^{4}$ teólogo da virada dos séculos XIX para XX com o ex-monge agostiniano de Wittenberg. Seria O Sagrado, no fundo, nada mais que uma atualização do pensamento de Lutero para os dias da Primeira Guerra Mundial, quando foi lançado? Que a ocupação com Lutero é, para Otto, bem mais que apenas episódio isolado, é fácil de imaginar quando se leva em consideração que já a tese doutoral, publicada em 1898, havia se ocupado com Lutero, especificamente com a pergunta pela compreensão do Espírito Santo, por aquilo que entrementes a teologia acadêmica se acostumou a denominar de Pneumatologia. ${ }^{5}$

A leitura que Otto faz de Lutero e a forma como se reporta ao Reformador para fundamentar sua concepção do "sagrado" enquanto numinoso que é experienciado como mistério tremendo e fascinante carregam as marcas do seu tempo - o que nem poderia ser

1 BOBSIN, Oneide. Prefácio à edição brasileira. In: OTTO, Rudolf. O Sagrado: os aspectos irracionais na noção do divino e sua relação com o racional. 4.ed. São Leopoldo: Sinodal/EST; Petrópolis: Vozes, 2017. p. 20.

2 BRANDT, Hermann. Apresentação. In: OTTO, Rudolf. O Sagrado: os aspectos irracionais na noção do divino e sua relação com o racional. 4.ed. São Leopoldo: Sinodal/EST; Petrópolis: Vozes, 2017. p. 13.

3 OTTO, 2017, p. 132-147.

4 Thorsten Dietz supõe que a diversidade das áreas de interesse, pesquisa e atuação de Otto possam ser um limite do grande estudioso. A variedade de interesse em um ou outro caso atraiu sobre Otto a suspeita de aplicar métodos questionáveis a seus objetos de investigação (cf. DIETZ, Thorsten. Der Neupietismus und die Theologie: biblische, missionarische und mystische Theologie bei Adolf Schlatter, Karl Heim und Rudolf Otto. In: LÜDKE, Frank. Was ist neu am Pietismus? Tradition und Zukunftsperspektiven der evangelischen Gemeinschaftsbewegung. Berlin: Literatur, 2010. [Schriften der Evangelischen Hochschule Tabor 1]. p. 122). O ecletismo de interesses pode ter levado Otto a ser estigmatizado como diletante.

5 OTTO, Rudolf. Die Anschauung vom heiligen Geiste bei Luther: eine historisch-dogmatische Untersuchung. Göttingen: Vandenhoeck \& Ruprecht, 1898. Para alguns dados biográficos sobre Otto, cf. KRAATZ, Martin. Art. Otto, Rudolf. In: Historische Komission bei der Bayerischen Akademie der Wissenschaften (Ed.). Neue deutsche Biographie. Berlin: Duncker \& Humboldt Gmbh, 1999. p. 709-711. v. 19: Nauwach Pagel. Uma visão panorâmica da forma como Otto lida com Lutero no decorrer da sua vida encontra-se em DIETZ, Thorsten. Die Luther-Rezeption Rudolf Ottos oder die Entdeckung der Kontrast-Harmonie der religiösen Erfahrung. In: DIETZ, Thorsten (Ed.) Rudolf Otto: Religion und Subjekt. Zürich: Theologischer Verlag Zürich, 2012. (Christentum und Kultur 12). p. 77-108. Th. Dietz constata três fases: a primeira está marcada pela tese doutoral, que Otto, em O Sagrado, retrospectivamente designa, de forma pejorativa, como "escrito de principiante [...] sob a influência de [Albrecht] Ritschl" (OTTO, 2017, p. 138). A segunda fase, que coincide com sua atuação em Göttingen até o convite a assumir uma cátedra em Breslau, em 1915, encontra-se sob a marca da apologia, p. ex., frente a cosmovisões marcadas por naturalismo e darwinismo. Neste período, Lutero é companheiro constante, ainda que Otto pouca referência explícita faça ao Reformador. A terceira etapa é representada por O Sagrado. 
diferente -, buscando respostas para perguntas que estão no ar e interpretando Lutero e outros autores do passado com as lentes interpretativas ou em diálogo crítico com essas lentes em uso na sua própria época. Do ponto de vista teológico, os desafios com os quais Otto se defronta se cristalizam na crise da Teologia Liberal e o unem, p.ex., ao Comentário à epístola aos Romanos, de Karl Barth, em 1919/1922, bem como à incipiente Teologia Dialética, ao "Socialismo Religioso", e à chamada renascença luterana representada por Karl Holl e outros. 6 A defesa dos elementos "helenísticos", em contraposição ao "jesuísmo" almejado por alguns no séc. XIX e no início do séc. XX,7 e a referência ao debate em torno da compreensão do "reino de Deus"8 são temas mencionados, de passagem, apenas no final de O Sagrado, mas que sinalizam a frente na qual Otto se vê laborando. ${ }^{9}$

Como bem observa Bobsin, não é apenas Lutero que inspira Otto, mas também a leitura da Bíblia. Impressiona a quantidade de referências e citações escriturísticas em uma obra que não pode propriamente ser considerada de cunho exegético. Cumpre, além disto, não ignorar as incontáveis referências à tradição mística pré- e pós-reformatória, protestante e católica, cristã e não-cristã, através da qual Otto não apenas interpreta Lutero, mas fundamenta sua própria concepção do que seja "o sagrado". De antemão seja

6 Cf. FISCHER, Hermann. Systematische Theologie. Konzeptionen und Probleme im 20. Jahrhundert. Stuttgart; Berlin; Köln: W. Kohlhammer, 1992. (Grundkurs Theologie. 6). p. 9-75. Sem poder, aqui, aprofundar a pergunta pela relação entre Otto e K. Barth, chama a atenção que a insistência de Otto em falar do mistério como o totaliter aliter ("totalmente outro"; cf. OTTO, 2017, p. 59 e passim) encontra um famoso correlato na afirmação de Barth na introdução à segunda edição do seu Comentario a Romanos: "se possuo um 'sistema', então ele reside no fato de eu procurar observar com a maior insistência possível e em seu significado positivo e negativo aquilo que Kierkegaard denominou de 'diferença qualitativa [infinita]' entre tempo e eternidade [Ecl 5.2]" (BARTH, Karl. A Carta aos Romanos: (segunda versão) 1922. Editado por Cornelis van der Kooi e Katja Tolstaja. Traduzido por Uwe Wegner. São Leoopoldo: Sinodal/EST, 2016. p. 50). Em sua referência à citada passagem de Barth, FISCHER, 1992, p. 28 transcreve por extenso o conhecido trecho de Ec 5.2: "Deus está nos céus, e tu, na terra" ("Gott ist im Himmel und Du auf Erden"). Acerca da "paradoxalidade do Cristianismo" ("Paradoxalität des Christentums") e da "irracionalidade das doutrinas cristãs" ("Unvernünftigkeit der christlichen Lehren") em Kierkegaard cf. informações mínimas em HORNIG, Gottfried. Lehre und Bekenntnis im Protestantismus. In: ANDRESEN, Carl (Ed.). Handbuch der Dogmen- und Theologiegeschichte. Em colaboração com Gustav Adolf BENRATH et al. Göttingen: Vandenhoeck \& Ruprecht, 1984. v. 3: Die Lehrentwicklung im Rahmen der Ökumenizität. p. 189-195. Sobre a recepção de Kierkegaard na Alemanha no início do séc. XX cf. DEUSER, Hermann. Art. Kierkegaard, Søren Aabye. Religion in Geschichte und Gegenwart. 4.ed. Tübingen: Mohr Siebeck, 2001. v. 4. col. 957s e HORNIG, 1984, p. 196s. De acordo com BARTH, HansMartin. Naturalismus, Darwinismus und das Heilige nach Rudolf Otto. Neue Zeitschrift für Systematische Theologie und Religionsphilosophie, Berlin: Walter de Gruyter, v.51, n.4, p. 445-460, 2009. p. 456, a recepção de $O$ Sagrado por K. Barth passou rapidamente de uma inicial reservada aceitação para uma clara rejeição. Cf. ainda a mesma afirmação do totaliter aliter divino em BULTMANN, Rudolf. Die liberale Theologie und die jüngste theologische Bewegung. In: BULTMANN, Rudolf. Glauben und Verstehen. 9.ed. Tübingen: J.C.B.Mohr (Paul Siebeck), 1993. v. 1. p. 1-25. Bultmann expressamente menciona Otto como representante de todo um movimento de diálogo crítico com a Teologia Liberal. Bultmann, porém, se distancia do adjetivo "irracional" em relação a Deus, também quer fazer uma clara distinção entre fé e mística. Estes e outros elementos levam Bultmann a, apesar dos paralelismos reconhecidos (cf. BULTMANN, 1993, p. 22), distanciar-se da concepção de Otto.

7 Cf. HORNIG, 1984, p. 210-216 (sobre Adolf von Harnack).

8 Cf. HORNIG, 1984, p. 204-208 (sobre A. Ritschl).

9 Cf. OTTO, 2017, p. 195-204.

Protestantismo em Revista | São Leopoldo | v. 44, n. 01 | p. 03-20| jan./jun. 2018

Disponível em: <http:// periodicos.est.edu.br/index.php/nepp> 
dito que a fundamentação bíblica e a referência à mística são, à sua maneira, parte da forma como Otto se reporta a e interpreta Lutero e a tradição teológica que lhe segue.

Com esses elementos - o contexto teológico-histórico imediato no início do séc. XX; a inspiração na Bíblia, em Lutero e na mística; a influência de e a reflexão crítica sobre Kant, Schleiermacher, Söderblom ${ }^{10}$ e outros - em mente, volto-me, pois, à pergunta específica deste artigo pela relação de Rudolf Otto com Martim Lutero conforme transparece em $O$ Sagrado.

\section{A relação de Rudolf Otto com Lutero em "O Sagrado" As referências de Otto a Lutero}

O capítulo sobre "o numinoso em Lutero", em O Sagrado, ${ }^{11}$ inicia com uma comprimida análise da história do pensamento anterior ao séc. XVI. Otto entende que, embora seja uma simplificação, a distinção da história do pensamento essencialmente em uma vertente platônica e outra aristótelica seja adequada. Sem dizê-lo expressamente, Otto localiza Lutero na linhagem platônica. Explicitamente afirma que no lado platônico estão não apenas o próprio Platão, mas também o neo-platônico Plotino, e Dionísio que, neste caso, não é o deus grego do vinho e da alegria, mas referência ao conjunto de dez cartas e quatro tratados conhecidos atualmente pelo nome de "Pseudo-Dionísio Areopagita".12 O quanto Otto deve ter se identificado com Pseudo-Dionísio ilustra a seguinte síntese do pensamento do Areopagita formulada por Volker Leppin: "[...] a realidade da verdade, a realidade de Deus não é atingível mediante esforços da capacidade humana de compreensão, enquanto esta procede de forma discursiva, isto é, na forma de distinções".13

10 Cf. BRANDT, 2017, p. 13. Segundo DOLE, Andrew. Schleiermacher and Otto on religion. Religious Studies, Cambridge, v. 40, n. 4, p. 389-413, dez. 2004, a concepção usual que vê em Otto um "fiel seguidor e fomentador" ("faithful follower and developer"; DOLE, 2004, p. 389) da teologia de Schleiermacher precisa ser revista. Para Dole, o pensamento de Otto é carregado de um ímpeto anti-naturalista, supranaturalista, contrário à compreensão naturalista da religião em Schleiermacher. Não no "pai da Igreja da teologia (neo)protestante", mas no pouco conhecido contemporâneo de Schleiermacher Jakob Friedrich Fries ( $\left.{ }^{*} 1773-+1843\right)$, lido por Otto à luz do pensamento de Kant, deveriam ser buscados os aportes filosóficos fundamentais da concepção de "sagrado" em Otto. O próprio Fries se compreendeu como parte de uma tradição iluminista-kantiana, em relação crítica ao Idealismo Alemão de Hegel e outros (cf. ROSENAU, Hartmut. Art. Fries, Jakob Friedrich. Religion in Geschichte und Gegenwart. 4.ed. Tübingen: Mohr Siebeck, 2000. v. 3. col. 381s).

11 OTTO, 2017, p. 132-147. Onde são comentadas passagens de O Sagrado sem indicação páginas, trata-se da passagem mencionada.

12 Cf. LEPPIN, Volker. Die christliche Mystik. Munique: C.H.Beck, 2007. (C.H.Beck Wissen in der Beck'schen Reihe). p. 25-39. Em uma das cartas, o autor se autodenomina Dionísio, insinuando, assim, uma proximidade com o apóstolo Paulo (cf. At 17.34). A homonimia entre o Pseudo-Areopagita e o deus grego poderia sugerir um curioso paralelo, pois tanto um quanto o outro são vinculados a experiências de êxtase; evidentemente, de cunho completamente distinto (cf. Ef 5.18). O paralelo precisa ser ainda mais relativizado se for levado em conta que o êxtase do qual o místico do séc. V fala não é um "evento afetivo ou emocional" ("nicht, dass es sich um einen affektiven oder emotionalen Vorgang handelt"; LEPPIN, 2007, p. 33).

13 "[...] die Wirklichkeit der Wahrheit, die Wirklichkeit Gottes, durch Anstrengungen des menschlichen Begriffsvermögens nicht erreichbar ist, sofern und so lange dieses diskursiv, und das heisst auch: unterscheidend, vorgeht" (LEPPIN, 2007, p. 28). 
Segundo Pseudo-Dionísio, os mistérios divinos têm sua causa no fato de o divino, Deus, ser inominável, apesar dos muitos nomes divinos testificados na Escritura. Deus é aquele que está acima de tudo o que é pessoal. Talvez seja adequado caracterizar esta forma de pensar e falar de Deus pelo Areopagita como sendo supraracional. A concepção do místico medieval converge com Otto na convicção de que Deus (ou: o numinoso) não pode ser subordinado à e domesticado pela capacidade da razão, ${ }^{14}$ pois Deus é totaliter aliter, completamente diferente de tudo que o ser humano possa pensar ou dizer a Seu respeito.

A contraposição entre atitude "teológico-aristotélica" e "religioso-platônica" sintetiza a crítica sistemática de todo O Sagrado ao racionalismo, ainda que também os platônicos não estejam imunes a ele. Na avaliação de Otto, o racionalismo amputou a vivacidade de Deus e lhe atribuiu apatia, incapacidade de sentimentos. ${ }^{15}$ Negando a vivacidade de Deus, extirpou dele não apenas a ira, mas também o amor, pois um não é possível sem a outra. ${ }^{16}$

Ao contrário dos liberais, que o trataram como "resquício escolástico de especulação nominalista",17 Lutero, destaca Otto, estava ciente desse aspecto "irracional" de Deus. Não no ocamismo-nominalismo, mas na mística Otto localiza a origem desta percepção do Reformador. Segundo Otto, a influência da mística sobre Lutero decresceu no curso dos anos, mas nunca se extinguiu. ${ }^{18}$ Otto se interessa exatamente pelas

14 Cf. p. ex. a opinião de Otto, segundo a qual "nome" - Otto se refere a um exemplo extraído do Fausto, de Goethe - "equivale a conceito" (OTTO, 2017, p. 33).

15 A "doutrina da apátheia" teria sido ressuscitada no Protestantismo a partir do teólogo luterano ortodoxo Johann Gerhard (cf. OTTO, 2017, p. 147). Cf. também a avaliação de que "até certo ponto [...] está correta" a "tese de que a ortodoxia teria sido ela própria a mãe do racionalismo" em OTTO, 2017, p. 35.

16 HORNIG, 1984, p. 207 descreve a imagem de Deus proposta por Albrecht Ritschl, expoente liberal do séc. XIX, como "concentrado na ideia do amor, ao passo que concepções como santidade divina e ira de Deus sobre o pecado são extirpadas" ("konzentriert sich auf den Liebesgedanken, wobei die Vorstellungen von der Heiligkeit Gottes sowie vom Zorn Gottes über die Sünde ausgeschieden werden"). H. Richard Niebuhr é citado por HORNIG, 1984, p. 206 em sua avaliação do protestantismo liberal estadunidense na virada para o séc. XX: "um Deus sem ira conduzia pessoas sem pecado a um reino sem juízo através de um Cristo sem cruz" ("ein Gott ohne Zorn leitete Menschen ohne Sünde in ein Reich ohne Gericht durch die Vermittlung eines Christus ohne Kreuz").

17 OTTO, 2017, p. 135. As aspas já se encontram no texto de Otto.

18 No que OTTO, 2017, p. 135 essencialmente é confirmado por pesquisas recentes. Enquanto Otto, porém, insinua uma linha que une Lutero a Dionísio, a pesquisa posterior afirma que o Reformador desde sempre se manteve arredio ao Areopagita, relativamente aberto a Bernardo de Claraval e completamente simpático a João Tauler (a cuja concepção de união mística OTTO, 2017, p. 143 faz referência) (cf. DIETZ, Martin Timóteo. De libertate et servitute spiritus. Pneumatologie in Luthers Freiheitstraktat. Forschungen zur systematischen und ökumenischen Theologie. v. 146. Göttingen; Bristol: Vandenhoeck \& Ruprecht, 2015. p. 122). Também a percepção de que Lutero crescentemente substitui "amor a Deus" por "fé" (cf. OTTO, 2017, p. 143) continua válida (cf. HAMM, Berndt. Von der Gottesliebe des Mittelalters zum Glauben Luthers - ein Beitrag zur Bussgeschichte. In: HAMM, Berndt. Der frühe Luther. Etappen reformatorischer Neuorientierung. Tübingen: Mohr Siebeck, 2010. p. 1-24). Em uma nota de rodapé, Otto insiste que não se deve procurar por "ligações de Lutero com especulação nominalista, mas com sentimentos elementares da religiosidade popular viva, particularmente da religiosidade camponesa" (OTTO, 2017, p. 135). Em que medida é adequado falar de "religiosidade camponesa", precisaria ser melhor analisado. O caráter popular da tradição mística, por sua vez, pode ser tranquilamente afirmado, especialmente se for levado em consideração o forte elemento leigo presente em seu meio (cf. LEPPIN, 
"espantosas especulações"19 de Lutero que, em sua obra sobre a vontade cativa contra Erasmo, havia feito a distinção entre o Deus revelado e o Deus não revelado, Deus em sua majestade. ${ }^{20}$ Erasmo, em seu escrito em defesa do livre arbítrio, havia argumentado que a Escritura Sagrada não é clara a respeito de diversas questões. ${ }^{21} \mathrm{~A}$ isto Lutero retruca com a distinção entre a Escritura e Deus, entre criatura e Criador. Enquanto, segundo Lutero, é evidente que "há muitas coisas abscônditas em Deus", que ignoramos, o mesmo não pode ser dito a respeito da Escritura. Todo o tratado sobre a vontade cativa, em última análise, nada mais é do que uma defesa da clareza da Escritura no tocante aos temas centrais da mensagem cristã - Lutero menciona a doutrina da Trindade e a Cristologia - e uma apologia ao direito de Deus de ser o senhor de todas as coisas, em sua majestade incompreensível ao ser humano.

Como bem formula Otto, Da Vontade Cativa toma sobre si a tarefa de conjugar a onipotência de Deus com a Sua graça. Pois a preocupação de Erasmo consiste na pergunta: se, para a salvação, tudo depende de Deus, não seria Ele injusto ao operar a fé em algumas pessoas, mas não em outras? Lutero se propõe a mostrar a Erasmo que a onipotência divina - que não afirma somente uma possibilidade de Deus, mas seu efetivo tudo-fazer não se contrapõe nem à graça, nem à justiça do Criador. Otto, por sua vez, percebe em Lutero um aliado em sua compreensão de Deus como mistério não apenas fascinante, mas também tremendo. Deus, diz Otto, não apenas atrai, mas também afasta. Em linguagem teológica tradicional: Deus não é apenas Deus da graça, mas também da ira. Ainda que não cite nomes, as reflexões de Otto neste tocante mal disfarçam o fato de não serem apenas intuições teóricas, mas percepções que reagem ao que lhe parece ser um processo

Volker. Espiritualidade na Idade Média tardia. In: KAUFMANN, Thomas et al. (Org.). História Ecumênica da Igreja. São Paulo: Loyola: Paulus; São Leopoldo: Sinodal, 2014. v. 2: da alta Idade Média até o início da Idade Moderna. p. 207-214). Não por último no que diz respeito à relação de Lutero com a tradição nominalista, a avaliação de Otto igualmente aponta na direção correta. Pois, embora Lutero tenha sido instruído na via moderna, naquilo que ele mesmo denominou de "Escola de [Guilherme de] Occam", seu desenvolvimento teológico como integrante da Ordem dos Agostinianos Eremitas fez dele um admirador do patrono da referida Ordem. Assim, por exemplo, em Da Vontade Cativa (cf. LUTERO, Martinho. Da Vontade Cativa. Da Vontade Cativa. In: In: LUTERO, Martinho. Obras Selecionadas. São Leopoldo: Sinodal; Porto Alegre: Concórdia, 1993. v. 4. p. 31, 33). Lutero recorre à ideia da potentia absoluta de Deus, interpreta-a, porém, não em viés pelagiano, tradicional nos círculos modernos, mas de maneira antipelagiana, na esteira de Agostinho e, sobretudo, da sua maneira de ler e interpretar a Escritura (cf. LEPPIN, Volker. B.I.6. Universitätswissenschaft. In: BEUTEL, Albrecht (Ed.). Luther Handbuch. Tübingen: Mohr Siebeck, 2005. p. 62-67).

19 O fato de a expressão estar entre aspas no texto de Otto insinua que se trata de uma referência ao modo como um terceiro se referiu ao que Lutero afirma. Aquilo que provoca escândalo entre alguns, como se não passasse de "mirae speculationes", é exatamente o que Otto, não sem uma pitada de ironia, julga ser o essencial.

20 Cf. LUTERO, 1993, p. 23-26.

21 Cf. ERASMUS VON ROTTERDAM. De libero arbitrio DIATRIBH sive collatio / Gespräch oder Unterredung über den freien Willen. Traduzido, introduzido e acrescido de notas por Winfried LESOWSKY. In: ERASMUS VON ROTTERDAM. Ausgewählte Schriften. Edição em oito volumes latim e alemão. Editado por Werner WELZIG. Darmstadt: Wissenschaftliche Buchgesellschaft, 1969. v. 4. p. $10 / 11-12 / 13$.

Protestantismo em Revista | São Leopoldo | v. 44, n. 01 | p. 03-20| jan./jun. 2018

Disponível em: <http:// periodicos.est.edu.br/index.php/nepp> 
de domesticação de Deus, que transformou o Pai de toda a graça em "alguém bocejando", "cornudo" ou "homem bonzinho". ${ }^{22}$

Na palavra, Deus se revela, manifesta Seu propósito salvífico, destaca Otto com Lutero. E, no entanto, um como outro conhecem também o "Deus em si mesmo", Deus nudus ("Deus nu") em sua majestade. Esse Deus é o santo que Lutero conheceu, mas foi esquecido no luteranismo posterior. A santidade de Deus, na opinião de Otto, nada mais é do que aquilo que os místicos denominaram de Sua "ira". Pois a santidade divina destrói e tem que destruir o ser humano pecador, como bem intuiu o profeta, em Is 6.5, à vista do Deus triplamente santo, e como, à sua maneira, indiretamente reconheceu Pedro, em Lc 5.8. ${ }^{23}$

Este Deus tremendo em Sua majestade carrega traços demoníacos. "[Deus] é até mais aterrador do que o diabo", Otto cita uma prédica de Lutero de 1524 sobre Ex 9, a passagem bíblica que narra o endurecimento de Faraó. ${ }^{24} \mathrm{Sim}$, pois Deus faz coisas que parecem contradizer, não apenas em parte, mas diametralmente, Sua infinita bondade. Deus não somente permite que Faraó se enrede em suas próprias tramas, mas ativamente trucida $^{25}$ o rei do Egito. É contra este Deus cuja identidade permanece incerta que Jacó tem que lutar no vau de Jaboque. ${ }^{26}$ Não apenas a identidade do contraente de Jacó/Israel permanece obscura como a luta que a pessoa cristã trava com Deus é embate cujo fim é incerto: haverá salvação ou condenação?27 A "palavra"28 é refúgio contra esse Deus escondido, "abscôndito em majestade". ${ }^{29}$ Sim, para Lutero - e Otto o segue -, o Deus que se

22 OTTO, 2017, p. 137. As expressões entre aspas são formulações de Lutero extraídas de uma prédica do Reformador sobre Dt 4, proferida em 1529 (que OTTO, 2017, p. 136 erroneamente informa ser sobre Êx 20). A citação que Otto extraiu da Edição de Erlangen encontra-se também em: LUTHER, Martin. Predigten über das fünfte Buch Mose. 1529. D. Martin Luthers Werke: kritische Gesamtausgabe. v. 28. Weimar: Hermann Böhlaus Nachfolger, 1903. p. 559.

23 Cf. OTTO, 2017, p. 90.

24 OTTO, 2017, p. 137. Também esta passagem citada por Otto a partir da Edição de Erlangen encontra-se na edição de Weimar: LUTHER, Martin. Predigten über das zweite Buch Mose. 1524-1527. D. Martin Luthers Werke: kritische Gesamtausgabe. v. 16. Weimar: Hermann Böhlaus Nachfolger, 1899. p. 141. A referência a edição de Erlangen "[v.] 85, [p.] 166" em OTTO, 2017, p. 139 parece conter um erro de digitação (já existente na versão alemã: cf. OTTO, Rudolf. Das Heilige. Über das Irrationale in der Idee des Göttlichen und sein Verhältnis zum Rationalen. Munique: Verlag C.H.Beck, [1963] 2004. p. 125). Correto é, provavelmente: "35, 166". Sobre o endurecimento de Faraó Lutero também reflete extensamente em $D a$ Vontade Cativa (cf. LUTERO, 1993, p. 116-142).

25 Esta, a expressão que Lutero usa em sua explicação de Dt 4 (apud OTTO, 2017, p. 137).

26 Cf. Gn 32.24-32.

27 Cf. BAYER, Oswald. A teologia de Martim Lutero: uma atualização. São Leopoldo: Sinodal, 2007. p. 145-148.

28 OTTO, 2017, p. 136.

29 LUTERO, 1993, p. 101. OTTO, 2017, p. 139 concede a quem interessar que Lutero também pode falar de forma edificante "que 'nosso Deus é um Senhor surpreendente"'. Certamente Otto sabia que a tradução de Isaías 45.15 na Vulgata fala exatamente de "Deus absconditus" (cf. Nova Vulgata. Bibliorum Sacrorum Editio. Sacrosancti Oecumenici Concilii Vaticani II Ratione Habita Iussu Pauli PP. VI Recognita Auctoritate Ioannis Pauli PP. II Promulgata. In: <http://www.vatican.va/archive/bible/nova_vulgata/documents/nova-vulgata_index_lt.html>. Acesso: 16.03.2018). A versão revista e atualizada de João Ferreira de Almeida traduz como "Deus misterioso". 
revela em Sua infinita bondade, como "forno ardente cheio de amor", não é o Deus majestoso, mas o Deus pregado, anunciado pela palavra. O Deus majestoso apenas pode ser temido, mas não amado. Nele não se pode confiar. O Deus majestoso é aquele que arranca dos seus fiéis o clamor: "Por que me desamparaste?", 30 que na hora da precisão, da provação, ${ }^{31}$ parece abandonar os que nEle confiam e por Ele esperam. O Deus nudus em sua majestade é, também, o Deus mutus (mudo), que rompe o diálogo com a Sua criatura. Privada da palavra divina, a criatura se torna refém da morte e irremediavelmente perdida. ${ }^{32}$ A fim de fugir da perdição, socorre-se junto ao Deus pregado contra o Deus majestoso.

Como "conjunto de idéias do tipo Jó"33 Otto designa aquilo que descreve em sua obra. Ele tem a ver com "a tremenda majestade do nume", de Deus, com "o espantoso, incompreensível, paradoxal", que não apenas está além e acima de toda a razão como graça que aperfeiçoa a natureza, mas "se opõe ao racional", à "prostituta Razão",34 da qual fala Lutero. Fundamentação de sua perspectiva Otto encontra na preleção de Lutero sobre a Carta do apóstolo Paulo aos Romanos, de 1515-1516, onde o professor de Wittenberg fala da vida oculta sob a morte e do caráter essencialmente negativo dos atributos divinos. Na forma como se apresenta, a formulação de Lutero parece remeter à "teologia negativa" do inefável, de Deus como totaliter aliter. Enquanto, porém, para o professor de Wittenberg, é necessário falar de Deus e Seu agir salvador sub contrario - de "amor por nós sob ódio contra nós, glória sob vergonha, salvação sob perdição, reino sob miséria, céu sob inferno, sabedoria sob tolice" 35 -, os místicos de linhagem (neo)platônica como o Areopagita36 iam além, ao afirmarem que mesmo a negação é inadequada para se falar de Deus e Sua absoluta transcendência. Em sua consequência, esta perspectiva leva "a sempre maior pobreza de palavras até finalmente à completa ausência de palavras". ${ }^{37}$

30 Sl 22.1; Mt 27.46.

31 Não é aqui o lugar para aprofundar-se na compreensão de tentatio como elemento constitutivo da existência cristã, na concepção de Lutero. Cf. apenas BAYER, 2007, p. 27-28.

32 LUTERO, 1993, p. 67: "Pois a vida sem a Palavra é incerta e obscura".

33 OTTO, 2017, p. 138.

34 OTTO, 2017, p. 138s.

35 "dilectio nostri sub odio nostri, gloria sub ignominia, salus sub perditione, regnum sub exilio, celum sub inferno, sapientia sub stultitia" (LUTHER, Martin. Vorlesung über den Römerbrief 1515/1516. Ed. latinaalemã. Weimar: Hermann Böhlaus Nachfolder, 1960. v. 2. p. 146/147). As expressões citadas foram omitidas por OTTO, 2017, p. 140.

36 Cf. STOLINA, Ralf. Art. Negative Theologie. Religion in Geschichte und Gegenwart. 4.ed. Tübingen: Mohr Siebeck, 2003. v. 6. col. 170-173.

37 "zu immer größerer Wortarmut bis schließlich [zu] völlige[r] Wortlosigkeit" (STOLINA, 2003, col. 171). Neste sentido, a teologia de Lutero se constitui em crítica a uma "teologia negativa" ou "apofática". A relevância atual de uma "teologia negativa" consiste, segundo STOLINA, 2003, p. 173, no reconhecimento da "permanente não-objetivação e não-subordinação" ("Nichtobjektivierbarkeit und Unverfügbarkeit") de Deus em relação ao ser humano e suas especulações. É neste aspecto que Otto identifica o ponto de contato entre o "conjunto de idéias do tipo Jó" e Lutero. 
$\mathrm{Na}$ doutrina da predestinação ${ }^{38}$ se cristaliza, de forma exemplar, a controvérsia que subjaz à discussão entre Erasmo e Lutero sobre servo ou livre arbítrio. Se o arbítrio humano é - completamente - cativo ${ }^{39}$ nas coisas concernentes a Deus e à salvação, como responsabilizá-lo, se negar-se à fé? Esta, a preocupação de Erasmo que Lutero refuta com base em Paulo e João. ${ }^{40}$ Deus não é injusto ao condenar o pecador, pois apenas lhe aplica a sentença que sua existência merece. Se possível fosse falar de uma injustiça divina, necessário seria falar da "injustiça" que o Senhor comete ao salvar pessoas que não o merecem. E: o que à "luz da natureza" é completo escândalo e mesmo a "luz da graça" resolve apenas parcialmente, a "luz da glória" há de desvelar por inteiro para demonstrar a plena justiça de Deus em todos os Seus feitos. ${ }^{41}$

\section{Elementos da teologia de Lutero em O Sagrado}

A breve passagem pelo capítulo sobre "o numinoso em Lutero", em O Sagrado, destacou vários temas típicos da teologia de Lutero aos quais Otto faz referência e com os quais trabalha. Cumpre, agora, explicitar esses temas sob uma perspectiva sistemática.

Ainda que não recorra explicitamente à fórmula "totaliter aliter" no capítulo sobre Lutero, é de se supor que ela seja uma, talvez até a chave por excelência para compreender a maneira como Otto recorre ao Reformador, especialmente a De servo arbítrio. Otto a utiliza no intuito de desconstruir o que ele diagnostica como um processo de racionalização e de moralização em curso na teologia e no falar e pensar sobre Deus.

A fórmula totaliter aliter em referência a Deus é recorrente na teologia alemã dos primeiros anos do séc. XX. Deus como "totalmente diferente" não pode ser encaixado e amarrado aos limites da razão humana, ao que Otto identifica como "racionalismo".42 $\mathrm{Na}$ avaliação de Otto, esse racionalismo "arrancou os dentes" de Deus, deixando-o banguela, inofensivo. Mas um Deus inofensivo, apático, é um Deus que também não pode amar. Quem nega Deus como tremendum, perde também o Deus fascinans. Não é possível ter um sem o outro. Por isso, Otto fala da ira de Deus. Ao falar da ira de Deus, à sua maneira Otto

38 Cf. OTTO, 2017, p. 141s.

39 Do ponto de vista de Lutero, o advérbio "completamente" nada mais representa do que uma redundância.

40 Cf. LUTERO, 1993, p. 181-214.

41 Cf. LUTERO, 1993, p. 214.

42 Cf. já o primeiro capítulo de O Sagrado em OTTO, 2017, p. 33-36. Como designação de um amplo leque de pensadores modernos, "racionalismo" se caracteriza pela convicção de que "a razão humana é origem, foco e norma do pensar e falar teológicos, [...] motivo pelo qual todas as doutrinas não compreensíveis à razão (especialmente Dogma da Trindade, Duas Naturezas de Cristo, Doutrina da Reconciliação e Escatologia) são sujeitos à crítica do dogma" ("die menschliche Vernunft Ursprung, Fokus und Norm theol[ogischen] Denkens und Redens schlechthin [ist], weswegen sämtliche der ratio nicht fassbaren Lehren (insbes[ondere] Trinitätsdogma, Zwei-Naturen-Lehre, Versöhnungslehre sowie Eschatologie) der Dogmenkritik unterzogen werden"; STEIGER, Johann Anselm. Art. Rationalismus III. Kirchengeschichtlich: Rationalismus und Supranaturalismus. Religion in Geschichte und Gegenwart. 4.ed. Tübingen: Mohr Siebeck, 2004. v. 7. col. 49). 
remete a Lutero e à sua compreensão de Lei como Palavra de Deus que condena o ser humano em seu pecado. Mas a referência à ira de Deus continua atual, segundo Otto, também para quem já ouviu e depositou sua confiança no Evangelho, a palavra da graça, da salvação. O Deus que, em Cristo, assumiu "forma de servo",43 nem por isso deixa de ser o Senhor. ${ }^{4}$ A Igreja e a Teologia do seu tempo, essa é a avaliação que transparece de $O$ Sagrado, literalmente domesticou o servo Jesus Cristo, julgou ter domínio sobre Ele, achou que o Pai de Jesus Cristo nem poderia outra coisa que não fosse "amar". De modo similar ao exílio babilônico dos judaítas, seis séculos antes do nascimento de Cristo, as experiências amargas da Primeira Guerra Mundial, entre 1914 e 1918, escancaram diante de Otto o fato de que Deus pode ainda bem outras coisas, além de amar. E, no entanto: se Deus, como disse Lutero, é um "forno ardente cheio de amor", amor inequivocamente revelado na encarnação do Verbo, Seu Filho Jesus Cristo, então as calamidades da Guerra têm que ser um questionamento radical a esse amor. Por mais evidentes que sejam a culpa e a responsabilidade humanas por essa e tantas outras tragédias, permanece a pergunta: e as vítimas inocentes, como ficam? O totaliter aliter de Otto fala também disto. O Deus que é "totalmente diferente" é o Deus que, na hora da necessidade, parece se esconder. Não apenas pessoas incrédulas, mas também, melhor, especialmente as crentes sofrem debaixo da tentatio, da provação, tentatio que, como destaca Lutero em De servo arbítrio, atinge seu ápice no terror diante da ameaça da condenação eterna.

Nesta dupla perspectiva, Deus é, pois, totaliter aliter: na Lei que condena a criatura pecadora; e no silêncio que não responde ao clamor das pessoas que a Ele levantam sua súplica. Esta segunda perspectiva Lutero e Otto descrevem como majestade de Deus. À primeira vista, a referência ao Deus absconditus em majestade parece ser uma contradição. Pois "majestade" insinua uma forma de revelação. As muitas referências bíblicas ao pavor evocado pela manifestação divina indicam, porém, na concepção de Lutero e Otto, que majestade não é forma de revelação, mas de ocultação divina. Pois quem conhece a Deus apenas em Sua majestade aterradora, não conhece o já mencionado "fogo ardente cheio de amor". Quem não conhece a Deus em Sua superabundante graça, não o conhece em Sua essência.

Esse conhecimento de Deus, porém, somente é possível sub contrario. Foi o que aconteceu, por exemplo, com Moisés, que pôde ver a Deus apenas por trás, pelas costas. ${ }^{45}$ As "costas de Deus" por excelência são o corpo triturado do Seu Filho Jesus Cristo, em que se revelam sua "dilectio sub odio", sua "gloria sub ignominia". Aqui está a majestade divina que não o esconde, mas o desvela, a glória divina que denuncia a maldade humana e anuncia a não-violência absoluta, o "forno ardente cheio de amor" de Deus. Este, porém,

\footnotetext{
$43 \quad$ Fp 2.6-7.

44 Cf. Jo 13.13s.

45 Cf. $\hat{E} \times 33.18-23$.
} 
não é o Deus da sabedoria pela qual pedem não apenas os gregos,46 mas é o Deus "totalmente diferente".

Que Deus é totaliter aliter não é, para Otto, em primeiro lugar uma afirmação ontológica, embora, evidentemente, também seja uma afirmação ontológica. Deus é Deus e nós não somos Deus. Neste sentido, Ele é "totalmente diferente" de nós. Mas, desde a encarnação do Verbo, Jesus Cristo, Deus também é ser humano, totaliter similis, "totalmente igual" a nós. Além disto, a Escritura testifica uma série de afirmações antropológicas que destacam a dignidade humana que - com todo o cuidado seja dito - declaram a proximidade entre o ser humano e seu Criador: começando pela afirmação da imagem e semelhança de Deus; ${ }^{47}$ passando pela admiração diante do fato de o ser humano ter sido criado, apenas "por um pouco, menor do que Deus";4 culminando com a provocativa afirmação de outro salmista: "Eu disse: sois deuses, sois todos filhos do Altíssimo". ${ }^{49}$ Mais grave que a diferença ontológica entre Deus e ser humano é a separação entre ambos causada pelo pecado. Por esta razão, penso que pode ser dito: Totaliter aliter é, para Otto, mais do que uma constatação ontológica, uma afirmação hamartiológica. A distinção entre Criador e criatura é, enquanto tal, somente uma diferença (como se isso fosse pouca coisa!). Separação, porém, apenas o pecado produz. ${ }^{50} \mathrm{Ou}$, então, de forma inversa: santidade, a santidade de Deus, produz separação de tudo aquilo que dela não compartilha. ${ }^{51}$ A razão que se arroga apropriar-se de Deus e definir o que pode ou não pode ser dito a respeito dEle, torna-se refém da hybris, cai em pecado. Em sua autossuficiência, mesmo que fosse infinita, a razão não seria capaz de captar a Deus em seu escândalo.

Além disto, o totaliter aliter de Otto se volta contra o que ele entende ser uma moralização "da idéia [sic!] de Deus".52 A Primeira Guerra Mundial havia esfacelado o otimismo dos teólogos liberais que acreditavam em um processo e progresso ético que levaria, afinal, à instauração do Reino de Deus. Nesse contexto vem - de certa maneira: tarde demais - o alerta de Otto: Deus e Seu Reino não podem ser identificados com algo

46 Cf. 1Co 1.22 .

47 Cf. Gn 1.27.

48 Sl 8.5.

49 Sl 82.6, ao qual Jesus faz referência em Jo 10.34. A sequência, porém, Sl 82.7, constata: "Todavia, como homens, morrereis e, como qualquer dos príncipes, haveis de sucumbir".

50 Cf. Is 59.2.

51 Cf. as reflexões em torno da etimologia e do uso de termos "santo", "sagrado" e "heil(ig)" em BRANDT, Hermann. Que implicam as palavras Das Heilige ou 'O Sagrado'?: reflexões interculturais lingüísticas [sic!], religioso-científicas e teológicas por ocasião da tradução brasileira da obra Das Heilige (O Sagrado) de Rudolf Otto. Estudos Teológicos, São Leopoldo, v. 48, n. 1, p. 18-38, 2008. Disponível em: <http://www3.est.edu.br/publicacoes/estudos_teologicos/vol4801_2008/et2008-1b_hbrandt.pdf>. Como bem observa BRANDT, 2008, p. 20, o título original alemão da obra de Otto, "Das Heilige", é um substantivo neutro que, por si só, "proíbe que se equipare simplesmente o Sagrado com o Deus ou um Deus entendido de forma pessoal (masculina!)". Apesar disto, penso não cometer injustiça contra Otto se identifico o numinoso, do qual fala a sua obra, com Deus.

52 OTTO, 2017, p. 120. Cf. OTTO, 2017, p. 111-131 (sobre o numinoso na Bíblia). 
que o fazer humano produz. A diferença entre o que o ser humano - na melhor das suas intenções, no ápice de sua capacidade e esforço - pode produzir não é apenas gradualmente distinto, mas totaliter aliter do Reino eterno que o Pai haverá de instaurar. ${ }^{53}$ Não a humanidade, também não a Igreja, caminha em direção ao Reino, mas espera pelo Reino que vem, enquanto suplica: "Venha o teu Reino". Nesta mesma direção aponta Lutero quando, ao polemizar contra a doutrina escolástica do mérito e suas sutilezas, afirma: "Pois o reino não está sendo preparado, mas está preparado; os filhos, porém, são preparados para o reino, não preparam o reino". ${ }^{54}$ Nos dias de Otto, a exegese bíblica ensinou a teologia a interpretar as parábolas de Jesus não mais como descrição de um processo que leva do aqui e agora para um lá e depois, mas como um contraste entre presente e futuro. ${ }^{55}$ Totaliter aliter é, pois, para Otto, um conceito escatológico. Os "sinais"56 que a Igreja e cada pessoa cristã colocam são ambivalentes e esperam pela avaliação definitiva do juízo final. O que é inequívoco ainda está por vir.

Se Deus, o numinoso, não pode ser abarcado nem por razão nem por moral, que caráter assume o relacionamento do ser humano com Ele? Para Otto, o relacionamento do ser humano com Deus se dá por meio da fé, a qual, na esteira de Lutero, é uma experiência "mística" e "irracional", é "emoção".57 Em O Sagrado, em dois momentos Otto se ocupa com uma "definição" de "irracional". No primeiro capítulo, 58 contrapõe "racional" e "irracional"; no décimo, 59 retoma a pergunta pelo significado de "irracional", constatando que a expressão em seus dias é uma espécie de palavra da moda, mas que carece de uma melhor definição. Para Otto, "irracional" se refere àquilo "que foge não ao nosso sentir, mas ao nosso pensar conceitual"; é o indizível, que opera "apenas com símbolos conceituais em vez de conceitos exatamente correspondentes". Assim sendo, o "irracional" não pode ser definido, mas, no máximo, descrito. Defini-lo equivaleria a racionalizá-lo. A literatura

53 Em sua discussão contra Erasmo, à sua maneira Lutero também destaca este aspecto ao enfatizar que não apenas os instintos "inferiores" da alma humana, mas também os "superiores", são carne, ou seja, estão irremediavelmente cativos sob o poder do pecado. Erasmo imagina uma espécie de zona neutra entre o bem e o mal, e o ser humano como alguém que pode livremente se inclinar para um lado ou para outro. Não assim Lutero, para quem cada pessoa é "cavalo", levado para onde o respectivo cavaleiro, Deus ou o diabo, quer (cf. LUTERO, 1993, p. 48-49, 161-162).

54 LUTERO, 1993, p. 111. Na página indicada, Lutero menciona expressamente tanto a bem-aventurança (Mt 25.34) quanto a condenação (Mt 25.41) proferida por Cristo a "ovelhas" e "cabritos". As obras que servem de critério para salvação ou condenação indicam que, embora o Reino não seja resultado do esforço humano, o pertencimento a Cristo tem a ver, de modo bem elementar, também com um fazer, ou seja: com ética.

55 Cf. BEINTKER, Michael. Art. Herrschaft Gottes/Reich Gottes VI/2. Neuzeit (ab 1789). Theologische Realenzyklopädie. Berlin/New York: Walter de Gruyter, 1995. v. XV: Heinrich II. - Ibsen. p. 226-228. A perspectiva futura do Reino testificada pelo Novo Testamento não ignora que, na pessoa de Jesus, este reino já está presente (cf. THEISSEN, Gerd; MERZ, Annette. O Jesus histórico: um manual. São Paulo: Loyola, 2002. [Bíblica Loyola 33]. p. 345). O evangelista João é exemplo proeminente desta dialética de escatologia presente e futura (cf. Jo 5.24-25).

56 Cf. novamente 1Co 1.22 .

57 Cf. OTTO, 2017, p. 143-144.

58 OTTO, 2017, p. 33-36.

59 OTTO, 2017, p. 97-99. Aqui se encontram as próximas citações no parágrafo. 
secundária interpreta o "irracional" de Otto, por exemplo, como "o estar dado pré-reflexivo da religião no sentimento", o "cerne pré-racional da experiência de Deus como o totalmente diferente", a "relação pré-conceitual com Deus". ${ }^{0}$ Se vejo bem, o "irracional" de Otto carrega elementos tanto suprarracionais quanto antirracionais como não-racionais.

O interesse de Otto em distinguir a fé tanto de um conhecer racional quanto de um fazer moral tem seu paralelo e correspondência em Lutero e em sua conhecida delimitação da fé, enquanto vita passiva, de teoria e prática. A fé, assim Lutero, é "uma experiência que eu não faço, mas sofro". 61 Não especulando nem operando, mas morrendo para renascer pela fé é constituída a pessoa cristã. Evidentemente que a existência cristã também tem a ver com conhecimento, p.ex., das narrativas bíblicas ou das doutrinas da tradição cristã. Na plena acepção da palavra, porém, a fé, como Lutero a compreende, é fiducia, confiança na promessa, no Evangelho de Jesus Cristo que anuncia eficazmente o perdão e opera justificação. Notitia, tomar conhecimento, e assensus ${ }^{62}$, assentir intelectualmente com alguma afirmação, ainda não fazem a fé em sua essência, embora a fides specialis, da qual Lutero fala, não exista sem alguma forma de conhecimento e assentimento teóricos. Além disto, a fé, como Lutero a compreende, também se relaciona com ética, moral, práxis, etc., ainda que não seja idêntica a elas. Sob suspeita de menosprezar as obras, Lutero enfatiza a importância das mesmas na vida da pessoa cristã. Nega, porém, que as obras constituam o cristão; pelo contrário, as obras pressupõem a pessoa cristã que é constituída pela fé, tal qual não são os frutos que constituem a árvore, mas a árvore que produz os frutos. ${ }^{63}$

A percepção de Otto remete não apenas a Lutero, mas retoma uma intuição que já fora desenvolvida por um teólogo que, na pesquisa, tem, não raro, sido percebido como estando distante do Reformador: Friedrich Schleiermacher. Não é aqui o lugar de analisar a relação de Otto com Schleiermacher - que, em O Sagrado, não é apenas de adesão e concordância -, mas é mais do que evidente o paralelismo com a reflexão de Schleiermacher que, na sua Fé Cristã, distingue a religião, como sentimento de

60 Na sequência: "präreflexive Gegebenheit der Religion im Gefühl"; "vorrationale[r] Kern der Erfahrung Gottes als des 'Ganz Anderen'"; "vorbegriffliche[] Gottesbeziehung" (Th. DIETZ, 2010, p. 118-119). O "sentimento", de Otto, remete a Schleiermacher. Enquanto este, porém, fala do "sentimento de dependência", Otto prefere falar em "sentimento de creaturidade". Th. DIETZ, 2012, p. 103 informa que o uso de "irracional" em Otto segue "um uso linguístico infeliz da época" ("einem unglücklichen Sprachgebrauch der Zeit folgend").

61 BAYER, 2007, p. 31-32.

62 Cf. DALFERTH, Ingolf U. Art. Glaube 3. Systematisch-theologisch. In: FAHLBUSCH, Erwin et al. (Ed.). Evangelisches Kirchenlexikon. Internationale theologische Enzyklopädie. 3.ed. (nova versão). Göttingen: Vandenhoeck \& Ruprecht, 1989. v. 2: G-K. col. 193-197.

63 Cf. LUTERO, Martinho. Das Boas Obras. In: LUTERO, Martinho. Obras Selecionadas. São Leopoldo: Sinodal; Porto Alegre: Concórdia, 1989. v. 2: O Programa da Reforma; Escritos de 1520. p. (97) 100-170; LUTERO, Martinho. Tratado de Martinho Lutero sobre a Liberdade Cristã. In: LUTERO, Martinho. Obras Selecionadas. São Leopoldo: Sinodal; Porto Alegre: Concórdia, 1989. v. 2: O Programa da Reforma; Escritos de 1520. p. (435) 436-460. 
dependência absoluta, de um saber e de um fazer ${ }^{64}$. Também a genealogia desta relação entre Lutero, Schleiermacher e Otto não pode ser aprofundada aqui. Imaginar elementos "místicos" como uma fonte comum, da qual Schleiermacher e Otto bebem não por último nas diversas formas de Pietismo, não deve ser de todo fantasioso. Em sua ênfase antinaturalista, porém, Otto se distancia expressamente de Schleiermacher. ${ }^{65}$

\section{Considerações finais}

As breves paráfrase e análise da forma como O Sagrado recorre a Lutero indicaram com bastante clareza sua, talvez até surpreendente, proximidade com o Reformador e com temas que lhe são caros. Evidentemente que não se trata de mera repristinação, muito menos de sujeição servil a um ícone do passado. Rudolf Otto lê e interpreta Lutero quatrocentos anos depois do início da Reforma, levando em consideração os desenvolvimentos históricos e teológicos ocorridos no período que o separa da primeira metade do séc. XVI e buscando responder aos desafios por eles colocados. No âmbito alemão da segunda década do séc. XX, Otto reage à crise da Teologia Liberal e procura em Lutero, leitor da Bíblia inspirado em Agostinho e em ares místicos, por novos caminhos para a Teologia e a Igreja dos seus dias. Como pessoa vastamente viajada, ${ }^{66}$ situa a mensagem cristã no contexto maior das religiões e dá seu aporte tanto de um ponto de vista missiológico ${ }^{67}$ quanto das Ciências das Religiões. Essa polivalência de Otto é, por um lado, um dos pontos fortes da sua obra; por outro, foi talvez a causa de rejeição e suspeita contra seu escrito.

A descrição de Deus, o numinoso, como tremendum e fascins é a forma que Otto usa para remeter à distinção entre as duas Palavras de Deus das quais fala Lutero: Lei e Evangelho. Uma leitura de Otto mais ciosa da teologia do Reformador poderia objetar que falta uma referência mais explícita, seja aos conceitos "Lei" e "Evangelho", seja à mediação verbal do anúncio da exigência e da graça divinas. Em contraposição, pode-se ponderar que o próprio Lutero não faz referência explícita a Lei e Evangelho de forma linear em seus escritos. Cada obra tem seu escopo específico, de maneira que alguns aspectos são destacados aqui; outros, lá. Além disto, deve-se levar em consideração a distinção entre

64 Cf. SCHLEIERMACHER, Friedrich. Der christliche Glaube nach den Grundsätzen der Evangelischen Kirche im Zusammenhange dargestellt. Republicado com base na segunda edição, em análise crítica do texto e acrescida de introdução, explicações e índices remissivos por Martin Redeker. Berlin: Walter de Gruyter \& Co., 1960. v. 1. p. 14-30 (\$§ 3-4).

65 Cf. OTTO, 2017, p. 41-42, 44, 49-50. Cf. também OTTO, 2004, p. 20, onde fica mais claro que o "de maneira nenhuma" do qual fala OTTO, 2017, p. 49 [nota de rodapé 28] não é uma afirmação genérica, mas direcionada especificamente contra Schleiermacher.

66 Cf. uma lista de países visitados por Otto em BRANDT, 2017, p. 12.

67 Cf. Th. DIETZ, 2010, p. 120-123 acerca do interesse de Otto pelo caráter missionário do Evangelho e pela evangelização de uma sociedade alemã (no primeiro quarto do séc. XX!) que se tornou "arreligiosa" ("religionslos"). A naturalidade com que Otto faz uso de exemplos do mundo das religiões para fundamentar sua concepção tem consequências missiológicas, na medida em que ele não compreende a fé cristã como estando em contraste absoluto com as demais religiões, mas percebe nelas paralelismos que podem servir de ponto de contato para a mensagem de Cristo. 
Palavra e Deus, que o próprio Lutero propõe em De servo arbitrio. ${ }^{68}$ No cânon dos loci teológicos, O Sagrado se situa na "Doutrina de Deus" ("Teologia"; "Gotteslehre"), aquele Deus do qual Lei e Evangelho dão testemunho. Se Otto, portanto, não recorre com maior ênfase à distinção entre as duas Palavras, não significa que ele não as tenha no radar. Pelo contrário: O Sagrado dá à leitora e ao leitor motivos para imaginar que a distinção entre Lei e Evangelho é uma chave hermenêutica crucial para a forma como a obra fala de Deus enquanto tremendum e fascins.

Ponderação similar pode ser contraposta a uma possível impressão que O Sagrado daria ênfase excessiva ao aspecto tremendum de Deus, à ira divina. Também neste quesito vale levar em consideração o escopo da obra. É evidente que o objetivo último de Deus é salvar, e que a Lei não é fim em si mesma, mas tem por objetivo apontar para o Evangelho. Otto, porém, teme que Lei e Evangelho não sejam apenas distinguidos, mas separados, de maneira que o Evangelho não seja mais compreensível como boa-notícia, se não for apreendido como mensagem de salvação para pessoas condenadas. Assim entendo o interesse de Otto no Deus que é tremendum, que Se ira. Esse interesse brota da distinção entre securitas, segurança, e certitudo, certeza da salvação. ${ }^{69}$ A segurança baseada num Deus "bocejando", "cornudo", "bonzinho",70 que nem pode outra coisa que não seja salvar, contrapõe-se à certeza sustentada no Evangelho que anuncia o Deus que condena o pecador para salvá-lo.

Em suma, faço minha a avaliação do teólogo alemão Thorsten Dietz, que reconhece em Rudolf Otto uma contribuição específica no contexto da retomada da pesquisa em Lutero, como ocorrida no chamado "renascimento de Lutero", no início do séc. XX. ${ }^{71}$ Otto merece ser levado a sério como pesquisador do Reformador e como teólogo luterano, relevante também ainda um século depois do lançamento de sua famosa obra. Atual continua não apenas sua contribuição teológico-sistemática no tocante à Doutrina sobre Deus ("Teologia"), mas também quanto à compreensão da fé como experiência sui generis distinta de um conhecimento teórico e do fazer moral, embora não dissociada destes. Igualmente atuais seguem, não por último, suas intuições a respeito das religiões, tanto na perspectiva da missiologia, quanto das Ciências das Religiões e sua relação com a Teologia.

68 Cf. LUTERO, 1993, p. 23.

69 Cf. LOCHMANN, Jan Milič. Art. Heilsgewissheit 2. Gewissheit - Sicherheit. In: FAHLBUSCH, Erwin et al. (Ed.). Evangelisches Kirchenlexikon. Internationale theologische Enzyklopädie. 3.ed. (nova versão). Göttingen: Vandenhoeck \& Ruprecht, 1989. v. 2: G-K. col. 469.

70 OTTO, 2017, p. 137.

71 Cf. Th. DIETZ, 2012, p. 98-104. Onde Th. Dietz julga ter que constatar diferenças entre Otto e Lutero, penso que elas têm mais a ver com o interesse específico de $O$ Sagrado do que com divergências teológicas substanciais. A constatação de uma "aprioridade da inclinação religiosa" (Th. DIETZ, 2012, p. 99; "Apriorität der religiösen Anlage") em Otto vincula-o a Schleiermacher de uma maneira da qual, em meu entender, Otto discordaria. E, reiterando: não se trata, como nem se deve tratar em qualquer caso, de repristinação. Fosse este o interesse de Otto, ele não escreveria $O$ Sagrado, mas se dedicaria à publicação das obras de Lutero (o que tampouco constituiria mera repristinação). 


\section{Referências}

A BÍBLIA SAGRADA. Antigo e o Novo Testamento. Traduzida em português por João Ferreira de Almeida. Revista e Atualizada no Brasil. 2.ed. Barueri: Sociedade Bíblica do Brasil, 1993.

BARTH, Hans-Martin. Naturalismus, Darwinismus und das Heilige nach Rudolf Otto. Neue Zeitschrift für Systematische Theologie und Religionsphilosophie, Berlin: Walter de Gruyter, v. 51, n. 4, p. 445-460, 2009.

BARTH, Karl. A Carta aos Romanos: (segunda versão) 1922. Editado por Cornelis van der Kooi e Katja Tolstaja. São Leoopoldo: Sinodal/EST, 2016.

BAYER, Oswald. A teologia de Martim Lutero: uma atualização. São Leopoldo: Sinodal, 2007.

BEINTKER, Michael. Art. Herrschaft Gottes/Reich Gottes VI/2. Neuzeit (ab 1789). Theologische Realenzyklopädie. Berlin/New York: Walter de Gruyter, 1995. v. XV: Heinrich II. - Ibsen. p. 226-228.

BOBSIN, Oneide. Prefácio à edição brasileira. In: OTTO, Rudolf. O Sagrado. Os aspectos irracionais na noção do divino e sua relação com o racional. 4.ed. São Leopoldo: Sinodal/EST; Petrópolis: Vozes, 2017. p. 19-22.

BRANDT, Hermann. Apresentação. In: OTTO, Rudolf. O Sagrado. Os aspectos irracionais na noção do divino e sua relação com o racional. 4.ed. São Leopoldo: Petrópolis; Sinodal/EST: Vozes, 2017. p. 9-17.

. Que implicam as palavras Das Heilige ou 'O Sagrado'?: reflexões interculturais linguísticas [sic!], religioso-científicas e teológicas por ocasião da tradução brasileira da obra Das Heilige (O Sagrado) de Rudolf Otto. Estudos Teológicos, São Leopoldo, v. 48, n. 1, p. 18-38, 2008. Disponível em:

<http://www3.est.edu.br/publicacoes/estudos_teologicos/vol4801_2008/et2008-

1b_hbrandt.pdf $>$.

BULTMANN, Rudolf. Die liberale Theologie und die jüngste theologische Bewegung. In: BULTMANN, Rudolf. Glauben und Verstehen. 9.ed. Tübingen: J.C.B.Mohr (Paul Siebeck), 1993. v. 1. p. 1-25.

DALFERTH, Ingolf U. Art. Glaube 3. Systematisch-theologisch. In: FAHLBUSCH, Erwin et al. (Ed.). Evangelisches Kirchenlexikon. Internationale theologische Enzyklopädie. 3.ed. (nova versão). Göttingen: Vandenhoeck \& Ruprecht, 1989. v. 2: G-K. col. 193-202.

DEUSER, Hermann. Art. Kierkegaard, Søren Aabye. Religion in Geschichte und Gegenwart. 4.ed. Tübingen: Mohr Siebeck, 2001. v. 4. col. 954-958.

DIETZ, Martin Timóteo. De libertate et servitute spiritus. Pneumatologie in Luthers Freiheitstraktat. Forschungen zur systematischen und ökumenischen Theologie. v. 146. Göttingen; Bristol: Vandenhoeck \& Ruprecht, 2015. 
DIETZ, Thorsten. Der Neupietismus und die Theologie: biblische, missionarische und mystische Theologie bei Adolf Schlatter, Karl Heim und Rudolf Otto. In: LÜDKE, Frank. Was ist neu am Pietismus? Tradition und Zukunftsperspektiven der evangelischen Gemeinschaftsbewegung. Berlin: Literatur, 2010. (Schriften der Evangelischen Hochschule Tabor 1). p. 89-124.

Die Luther-Rezeption Rudolf Ottos oder die Entdeckung der Kontrast-Harmonie der religiösen Erfahrung. In: DIETZ, Thorsten (Ed.) Rudolf Otto: Religion und Subjekt. Zürich: Theologischer Verlag Zürich, 2012. (Christentum und Kultur 12). p. 77-108.

ERASMUS VON ROTTERDAM. De libero arbitrio DIATRIBH sive collatio / Gespräch oder Unterredung über den freien Willen. Traduzido, introduzido e acrescido de notas por Winfried LESOWSKY. In: ERASMUS VON ROTTERDAM. Ausgewählte Schriften. Edição em oito volumes latim e alemão. Editado por Werner WELZIG. Darmstadt:

Wissenschaftliche Buchgesellschaft, 1969. v. 4. p. 1-195.

FISCHER, Hermann. Systematische Theologie. Konzeptionen und Probleme im 20. Jahrhundert. Stuttgart; Berlin; Köln: W. Kohlhammer, 1992. (Grundkurs Theologie 6).

HAMM, Berndt. Von der Gottesliebe des Mittelalters zum Glauben Luthers - ein Beitrag zur Bussgeschichte. In: HAMM, Berndt. Der frühe Luther. Etappen reformatorischer Neuorientierung. Tübingen: Mohr Siebeck, 2010. p. 1-24.

HORNIG, Gottfried. Lehre und Bekenntnis im Protestantismus. In: ANDRESEN, Carl (Ed.). Handbuch der Dogmen- und Theologiegeschichte. Em colaboração com Gustav Adolf BENRATH et al. Göttingen: Vandenhoeck \& Ruprecht, 1984. v. 3: Die Lehrentwicklung im Rahmen der Ökumenizität. p. 71-287.

KRAATZ, Martin. Art. Otto, Rudolf. In: Historische Komission bei der Bayerischen Akademie der Wissenschaften (Ed.). Neue deutsche Biographie. Berlin: Duncker \& Humboldt Gmbh, 1999. p. 709-711. v. 19: Nauwach - Pagel.

LEPPIN, Volker. B.I.6. Universitätswissenschaft. In: BEUTEL, Albrecht (Ed.). Luther Handbuch. Tübingen: Mohr Siebeck, 2005. p. 62-67.

. Die christliche Mystik. Munique: C.H.Beck, 2007. (C.H.Beck Wissen in der Beck'schen Reihe)

. Espiritualidade na Idade Média tardia. In: KAUFMANN, Thomas et al. (Org.). História Ecumênica da Igreja. São Paulo: Loyola: Paulus; São Leopoldo: Sinodal, 2014. v. 2: da alta Idade Média até o início da Idade Moderna. p. 195-221.

LOCHMANN, Jan Milič. Art. Heilsgewisshei 2. Gewissheit - Sicherheit. In: FAHLBUSCH, Erwin et al. (Ed.). Evangelisches Kirchenlexikon. Internationale theologische Enzyklopädie. 3.ed. (nova versão). Göttingen: Vandenhoeck \& Ruprecht, 1989. v. 2: G-K. col. 469.

LUTERO, Martinho. Das Boas Obras. In: LUTERO, Martinho. Obras Selecionadas. São Leopoldo: Sinodal; Porto Alegre: Concórdia, 1989. v. 2: O Programa da Reforma; Escritos de 1520. p. (97) 100-170. 
. Da Vontade Cativa. In: In: LUTERO, Martinho. Obras Selecionadas. São Leopoldo: Sinodal; Porto Alegre: Concórdia, 1993. v. 4. p. (11) 17-216.

. Tratado de Martinho Lutero sobre a Liberdade Cristã. In: LUTERO, Martinho. Obras Selecionadas. São Leopoldo: Sinodal; Porto Alegre: Concórdia, 1989. v. 2: O Programa da Reforma; Escritos de 1520. p. (435) 436-460.

LUTHER, Martin. Predigten über das fünfte Buch Mose. 1529. D. Martin Luthers Werke: kritische Gesamtausgabe. v. 28. Weimar: Hermann Böhlaus Nachfolger, 1903. p. (503) 509-763.

. Predigten über das zweite Buch Mose. 1524-1527. D. Martin Luthers

Werke: kritische Gesamtausgabe. v. 16. Weimar: Hermann Böhlaus Nachfolger, 1899. p. (XI)1-646.

. Vorlesung über den Römerbrief 1515/1516. Ed. latina-alemã. Weimar: Hermann Böhlaus Nachfolder, 1960. 2v.

Nova Vulgata. Bibliorum Sacrorum Editio. Sacrosancti Oecumenici Concilii Vaticani II Ratione Habita Iussu Pauli PP. VI Recognita Auctoritate Ioannis Pauli PP. II Promulgata. In: < http:/ / www.vatican.va/archive/bible/nova_vulgata/documents/novavulgata_index_lt.html>. Acesso: 16 mar. 2018.

OTTO, Rudolf. Das Heilige. Über das Irrationale in der Idee des Göttlichen und sein Verhältnis zum Rationalen. Munique: Verlag C.H.Beck, [1963] 2004.

. Die Anschauung vom heiligen Geiste bei Luther: eine historisch-dogmatische Untersuchung. Göttingen: Vandenhoeck \& Ruprecht, 1898.

. O Sagrado. Os aspectos irracionais na noção do divino e sua relação com o racional. 4.ed. São Leopoldo: Sinodal/EST; Petrópolis: Vozes, 2017.

ROSENAU, Hartmut. Art. Fries, Jakob Friedrich. In: Religion in Geschichte und Gegenwart. 4.ed. Tübingen: Mohr Siebeck, 2000. v. 3. col. 381s.

SCHLEIERMACHER, Friedrich. Der christliche Glaube nach den Grundsätzen der Evangelischen Kirche im Zusammenhange dargestellt. Republicado com base na segunda edição, em análise crítica do texto e acrescida de introdução, explicações e índices remissivos por Martin Redeker. Berlin: Walter de Gruyter \& Co., 1960. 2v.

STEIGER, Johann Anselm. Art. Rationalismus III. Kirchengeschichtlich: Rationalismus und Supranaturalismus. Religion in Geschichte und Gegenwart. 4.ed. Tübingen: Mohr Siebeck, 2004. v. 7. col. 49-52.

STOLINA, Ralf. Art. Negative Theologie. Religion in Geschichte und Gegenwart. 4.ed. Tübingen: Mohr Siebeck, 2003. v. 6. col. 170-173.

THEISSEN, Gerd; MERZ, Annette. O Jesus histórico: um manual. São Paulo: Loyola, 2002. (Bíblica Loyola 33). 